\title{
CONSERVAÇÃO DE FORRAGEM NA FORMA DE SILAGEM: UMA EXPERIÊNCIA DIDÁTICA E PRÁTICA
}

\section{FORAGE CONSERVATION IN THE FORM OF SILAGE: A DIDACTIC EXPERIENCE AND PRACTICE}

\author{
Robson Vinício dos Santos ${ }^{1}$; Marta Xavier de Carvalho Correia²; Mércia Cardoso da Costa \\ Guimarães $^{3}$; Paulo Márcio Barbosa de Arruda Leite ${ }^{4}$
}

DOI: https://doi.org/10.31692/978-65-991061-7-0.512-515

\section{INTRODUÇÃ̃O}

A conservação das plantas forrageiras é importante para o aproveitamento da forragem quando a mesma se encontra no seu melhor valor nutritivo e quantidade de matéria seca, para ser utilizada na alimentação animal nos períodos de escassez, minimizando custos (CRUZ et al., 2011).

O processo de conservação de forragem através de fermentações, em condições anaeróbicas é denominado ensilagem, seu produto é a silagem e o local de armazenamento é o silo. As fermentações ocorrem por reações químicas que resultam no desaparecimento parcial dos substratos e formação de ácidos orgânicos, aminas e amônia. Parte da biomassa é perdida em forma de calor e seus substratos são degradados a compostos mais simples ou são metabolizados pelos microrganismos e transformados em acetato, butirato e lactato. Essas perdas são parcialmente compensadas, pois a silagem resultante geralmente tem maior concentração energética que a forragem original (FONTANELI e FONTANELI, 2018).

$\mathrm{O}$ aluno monitor tem como atribuição auxiliar o professor em atividades teóricas e práticas, na preparação de material didático e experimental, na realização de trabalhos práticos e experimentais e em atividades de classe e/ou laboratoriais.

Objetivou-se relatar a experiência como monitor nas aulas sobre Conservação de Forragem para confecção de silagem, das disciplinas Plantas Forrageiras e Suinocultura, em duas turmas de alunos do curso Técnico em Agropecuária do Instituto Federal de Pernambuco - IFPE, campus Vitória de Santo Antão - PE, interligando a prática com a importância da conservação de forragem em propriedades rurais. Além disso, objetivou-se demonstrar novas técnicas e matérias acessíveis usados para beneficiar a silagem, fugindo da visão industrial que conta com a presença de grandes estruturas para executar a atividade.

\footnotetext{
${ }^{1}$ Agropecuária, IFPE - Campus Vitória de Santo Antão, robson4651 @ hotmail.com

${ }^{2}$ Professora, IFPE - Campus Vitória de Santo Antão, marta.xavier@vitoria.ifpe.edu.br

${ }^{3}$ Professora, IFPE - Campus Vitória de Santo Antão, mercia.guimaraes@ vitoria.ifpe.edu.br

${ }^{4}$ Professor, Serviço de Tecnologia Alternativa - SERTA, paulomarcio@ serta.org.br
} 


\section{RELATO DE EXPERIÊNCIA}

Inicialmente, realizamos debates com os alunos e professores sobre a importância de produzir silagem para alimentação dos animais ruminantes. Os alunos ficaram responsáveis de providenciar as forragens e os materiais necessários para execução da atividade prática (capim elefante, farelo de milho, melaço, garrafas PET's, fita adesiva, entre outros).

A silagem foi produzida a partir da utilização de garrafas PET's transparentes (Imagem 1), que facilitam a visualização de todo o processo de fermentação que ocorre dentro do silo. O material a ser ensilado foi o Capim Elefante Roxo de Botucatu (Pennisetum purpureum Schum) e os aditivos utilizados foram o farelo de milho e o melaço de cana-deaçúcar.

As turmas foram divididas em grupos, onde cada um ficou responsável em construir dois silos, um bem compactado e outro mal compactado, visando compreenderem a importância do processo e produção de silagem de boa qualidade, entendendo que quando o silo é mal compactado (presença de oxigênio), será produzido alimento impróprio para o consumo dos animais.

O tempo de fermentação depende, principalmente, do teor de carboidratos solúveis, da capacidade tampão e do teor de umidade da forragem (VAN SOEST, 1994). Após 21 dias da aula prática de ensilagem/turma realizou-se a abertura dos silos para avaliação da silagem produzida. Inicialmente apresentamos os critérios a serem utilizados (coloração, odor e pH) para avaliar uma boa silagem (Imagem 2), as fermentações que ocorrem dentro do silo, os ácidos orgânicos produzidos e a influência do aquecimento para a silagem.

Cada grupo realizou a abertura dos seus silos, avaliando os aspectos olfativos e visuais da silagem. Em seguida, foi usada a fita medidora de $\mathrm{pH}$ e água destilada (diluição de uma amostra da silagem), por ser uma água isenta de quaisquer sais, não interferindo no resultado (Imagem 3). Foram selecionadas as melhores silagens que estavam dentro dos critérios desejáveis para ser ofertada aos animais para avaliar a palatabilidade e aceitação desse alimento.

Uma das turmas ofertou a silagem aos bovinos (Imagem 4) e a outra aos caprinos e ambas as espécies consumiram bem. A oferta das silagens produzidas aos animais indicou que além de ensilar uma forragem, deve-se considerar o seu valor nutritivo e palatabilidade. 
Imagem 1 - Silos em garrafas PET's.

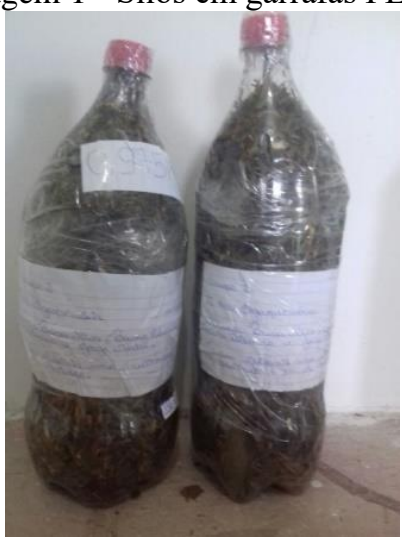

Fonte: Própria.
Imagem 4 - Oferta da silagem aos bovinos.

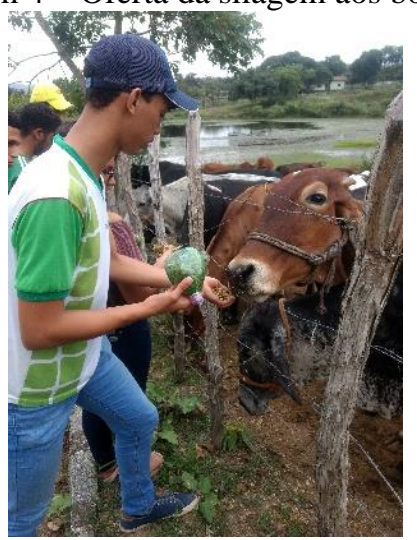

Fonte: Própria.

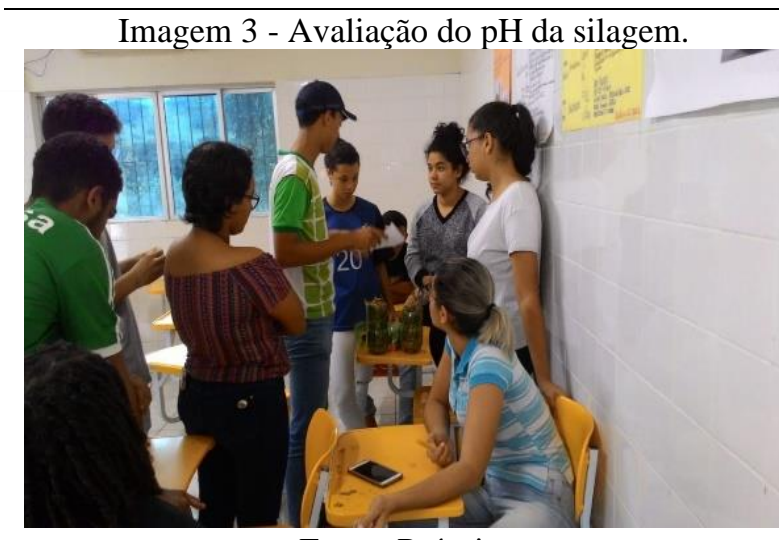

Fonte: Própria.
Imagem 2 - Demonstração dos critérios de avaliação da silagem.

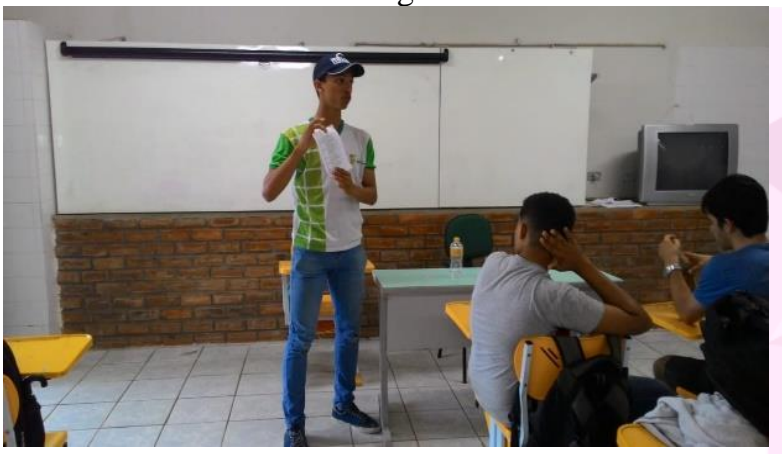

Fonte: Própria.

\section{CONSIDERAÇÕES}

Utilizando silos de garrafas PET's, foi possível demonstrar aos alunos de maneira simples e segura, o processo de ensilagem e sua importância na conservação de forragens para alimentação dos animais em períodos de escassez, bem como orientar, capacitar e despertar neles a necessidade de obter bons resultados através do uso de materiais existente na região e de baixo custo e que podem ser empregados corretamente.

As atividades teóricas e práticas possibilitaram maior aprendizado, sendo necessário planejamento anterior para que todas as etapas fossem realizadas. A participação como monitor foi importante através da interação com os alunos, conhecimentos e aquisição de novas habilidades: motivação dos grupos, segurança dos conteúdos, desempenho, liderança e paciência.

\section{REFERÊNCIAS}

CRUZ, J.C.; PEREIRA FILHO, I.A.; GONTIJO NETO, M.M.: Milho para silagem. Disponível 
4k3j537ooi.html. Acesso: 29/09/2017.

FONTANELI, R.S; FONTANELI, R.S. Ensilagem - Embrapa trigo. Disponível em: <http://www.cnpt.embrapa.br/biblio/li/li01-forrageiras/cap13.pdf>. Acesso em: 15/07/2018.

VAN SOEST, P.J. Nutritional ecology of the ruminant. 2.ed. Ithaca: Cornell University Press, 1994. $476 \mathrm{p}$. 
